\title{
SEX-LINKED WINGLESSNESS IN THE FOWL
}

\author{
F. M. LANCASTER \\ National Institute of Poultry Husbandry, Newport, \\ Shropshire
}

Received 15.ix.67

\section{INTRODUCTION}

Sex-linked winglessness in fowls was first described by Pease (1962). He received three female wingless chicks from a breeder in Devon who stated that no wingless cockerels had ever been observed. As a result of several small test matings Pease concluded that the gene concerned was a sex-linked recessive of variable expression which also affected the legs. In the most extreme cases the birds were completely limbless. The stock was handed over to the National Institute of Poultry Husbandry for further investigations.

Winglessness owing to an autosomal recessive was first noted by Waters and Bywaters (1943). They found that it varied in its expression from a facultative to an obligate lethal. The least extreme form of expression occurred in chicks which were normal in all respects except for the absence of wings or the presence of vestigial wing appendages. These appendages varied in length from rudimentary humeri, which failed to evaginate through the outer body surface, to nearly complete wings. The most extreme expression involved complete limblessness (legs and wings) combined in some cases with the absence of several internal organs including the respiratory and urinogenital systems. The following were also associated with the condition; syndactyly between the third and fourth digits, misplacement of the first toe, rudimentary scales on shanks and toes, down feathers present on shanks and toes, and ankylosis of the hock joint. Since no symbol was suggested by the authors Hutt (1949) assigned the letters wg to this gene.

The discussion which follows includes details of expressivity and linkage investigations into the sex-linked form of winglessness as described by Pease (loc. cit.).

\section{Materials}

The heterozygous males received from Pease were the products of mating between several autosexing breed males and some Buff Rock $\times$ Light Sussex wingless pullets from the original farm. These males were mated with normal Black Leghorn and Light Sussex females.

\section{Penetrance and expressivity}

There was no significant departure from the expected proportion of wingless chicks (table l) so penetrance appears to be complete. The nearest approach to nil penetrance was in fewer than 1 per cent. of the "wingless" chicks which appeared normal at day-old but developed wing abnormalities by 3 weeks of age. These abnormalities included drooping wings resulting from the inability of the birds to fold their wings close to the body. In some cases the wings trailed on the ground. The development 
of the flight feathers was also abnormal and occasionally supernumerary phalanges were present.

The expressivity of sex-linked winglessness followed very closely the pattern described by Waters and Bywaters (1943) for the autosomal form. The variation in degree of limblessness was almost identical but there was no involvement of the internal organs as in the autosomal type. Thus, the most extreme form of expression of this gene was almost complete normality except for the absence of limbs. The range of expression extended from this condition to almost nil penetrance as described above.

There was a modal type, comprising 35.6 per cent. of the "wingless" birds, where the hind limbs were normal but the front limbs were absent. Lower degrees of expressivity produced rudimentary wings of various sizes as described by Waters and Bywaters. Higher degrees caused shortening of the long bones of the leg or their absence; migration of number one digit

TABLE 1

Confirming sex linkage and complete penetrance of ws

The following offspring were hatched from nine different matings between heterozygous males and normal females:

( Ws ws ơ $\times W s$ -

$\begin{array}{ccc}\text { Winged males } & \text { Winged females } & \text { Wingless females } \\ 685 & 356 & 348\end{array}$

Agrees with $2: 1: 1$ ratio. $\chi^{2}$ about $0 \cdot 35 . \quad P=0 \cdot 8-0 \cdot 9$

to various abnormal positions on the foot and the leg; absence of $1,2,3$ or 4 digits; missing phalanges; ankylosis of the hock joint; syndactyly and two other peculiar conditions which are described below. The first involved the tibia which appeared to have broken and fused together again in an abnormal position before hatching. In some cases the resulting distortion was so great that the ventral surfaces of the feet were facing upwards. The second effect concerned the scales on the feet. The pattern on the upper surfaces was repeated again below so that virtually the soles of the feet were absent. This condition was usually accompanied by a flattening and softening of the leg bones.

When leg abnormalities occurred winglessness was usually complete but when rudimentary wings were present the legs were normal. Asymmetry of expression was fairly common but overlapping between rudimentary wings and affected legs on opposite sides was rare.

To measure the degree of expressivity an arbitrary scale was devised. Since the most extreme form observed was complete limblessness this condition was allotted 100 points and the modal type (normal legs but no wings) was given 50 points. Thus $0-50$ describes the degrees of rudimentation of the wings in birds with normal legs; whereas $50-100$ refers to wingless birds with varying amounts of leglessness.

The effect of modifying genes introduced from different breeds was clearly seen when the same male (A) which was heterozygous for winglessness was mated in shifts with two different breeds of normal females-matings 1 and 2 (table 2). From the first group of Light Sussex females (X) the mean expressivity score in the female "wingless" offspring was 55.0 with a 
range of 50 to 75 . From the second group consisting of 12 Black Leghorn females (Y) the mean score was 44.4 and the range 5 to 70 . In the second case only 7 of the 49 values were over 50 . Similar results were found when $F_{1}$ males ( $B$ and $C$ ) from the Light Sussex cross above (No. 1) were mated back to the original Light Sussex and Black Leghorn hens (mating numbers 3 and 6). In both cases the values were shifted in the direction expected from the results of the first two crosses (table 2). Finally, two further males (D and E) from the Light Sussex mating (No. 1) were crossed in turn with the same group of six of their wingless half-sisters $(\mathrm{Z})$-matings 7 and $7 \mathrm{~A}$. In this case there was an unexpected difference in the effect of the two males even though they were closely related (half-brothers).

Compared with normal chicks the presence of the "wingless" gene was found to reduce hatchability by 17 per cent. Furthermore, the hatchability of the wingless chicks also appeared to be affected slightly by the expressivity score as follows : average score of hatched wingless- $52 \cdot 7$, score of dead-inshell wingless-55.5. This difference was significant at the 5 per cent. level over all the chicks examined.

From matings Nos. 7 and 7A "wingless" males as well as "wingless" females were obtained. The scores of the two sexes were compared to see whether the homozygous condition of the male increased the expressivity of winglessness compared with the hemizygous condition of the female. In fact the females had a slightly higher score than the males but the difference was not significant at the 5 per cent. level of probability.

Many of the chicks examined showed asymmetry of expression as noted earlier. In all the matings except one (No. 7A) the mean values showed a slightly higher degree of expression on the right side than on the left. Disregarding the different matings the difference was significant at the 5 per cent. level of probability (table 2 ). Since 142 out of the 239 wingless chicks examined were symmetrical the asymmetry of the other 97 was greater than is apparent from table 2 . This difference may possibly be connected with the orientation of the embryo during its development.

Other manifestations of the gene for winglessness were a slight eye defect and underdevelopment of the breast musculature. Many of the " wingless" birds from a few days old to maturity had watery eyes, a condition not found in their normal sisters. Since no detailed examination of the eye was carried out it is not known whether this was due to a blocked tearduct or to some other cause. The poor development of the pectoral muscles was largely a result of the absence of wings.

A final condition which did not appear until the last generation and therefore could not be included in the expressivity rating was a slight shortening of the sternum.

Chicks of the modal type or with rudimentary wings were easy to rear and several pens of the former class were kept for future breeding stock. The average annual egg production in one pen of wingless pullets was 148 compared with 163 for their normal Light Sussex dams. In two separate comparisons between related birds the fertility was as follows:

1. Normal male $\times$ normal females Wingless male $\times$ wingless females

2. Normal male $\times$ normal females Normal male $\times$ wingless females
$69 \cdot 1$ per cent. $50 \cdot 6$ per cent. 63.0 per cent. 65.3 per cent. 


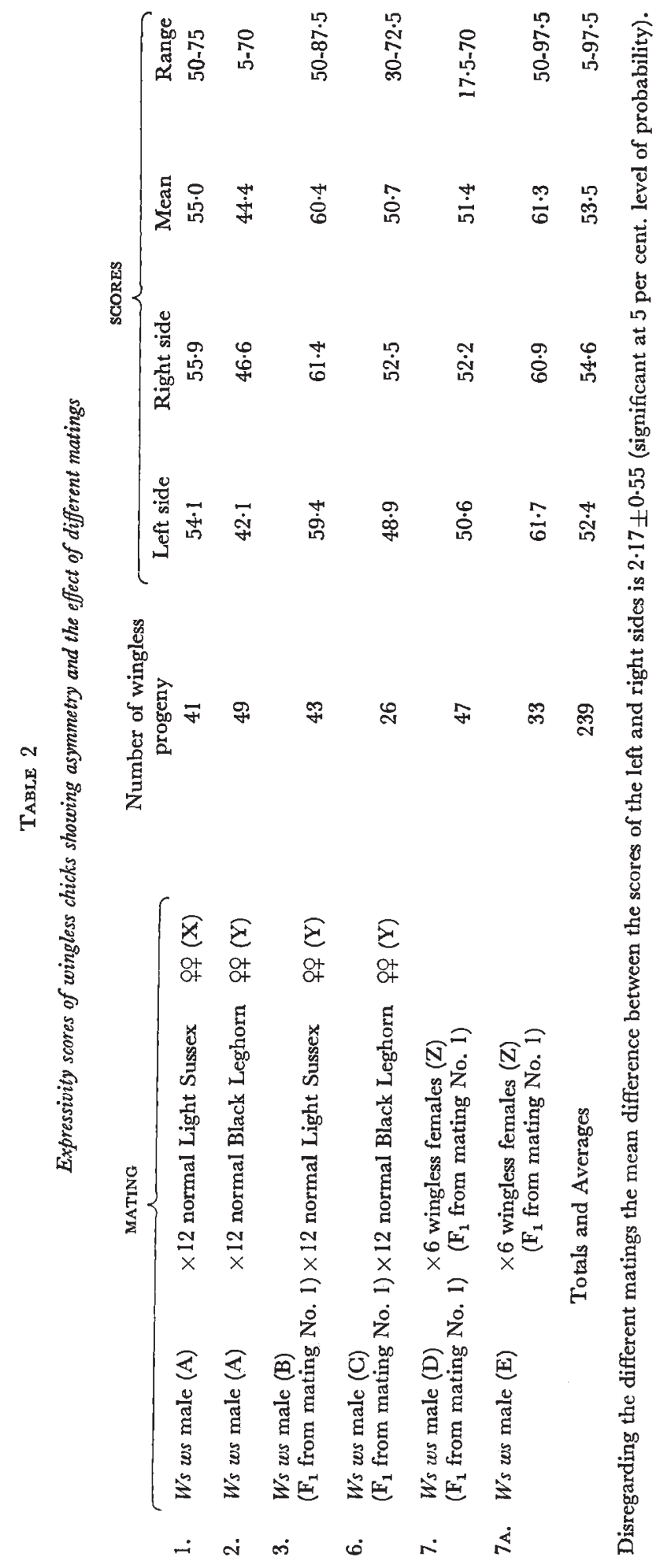




\section{Estimation of Recombination values}

The presence of "winglessness" on the sex chromosome was confirmed from various experimental matings. When known heterozygous males were mated to normal winged females they produced the ratios expected for a sex-linked recessive (table 1 ).

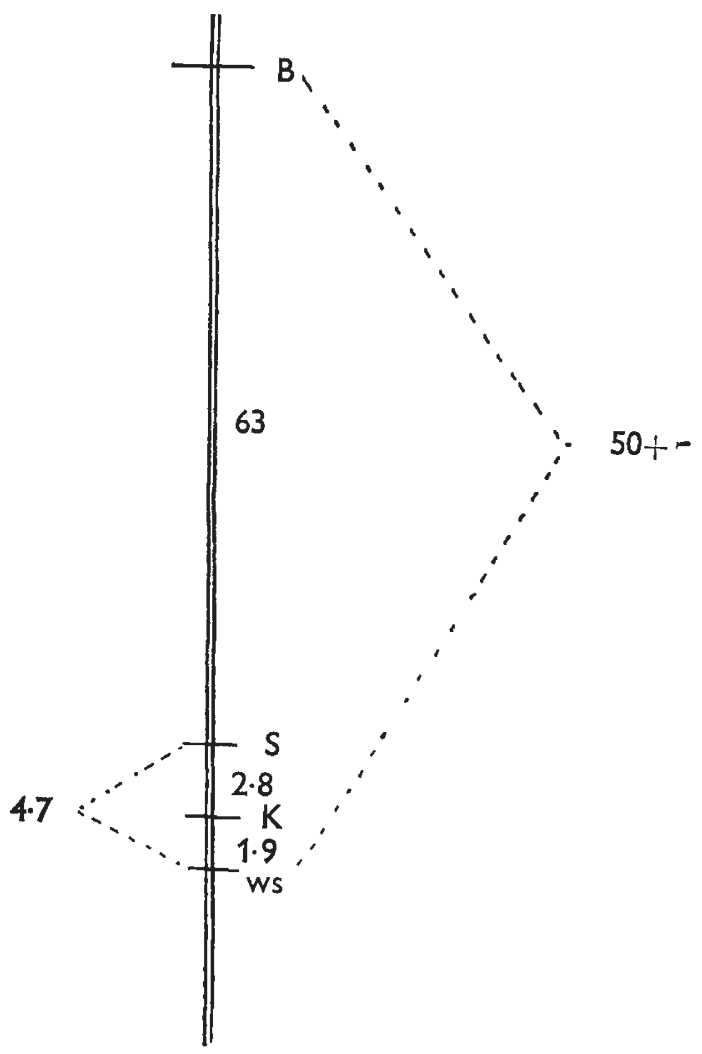

FIG. 1.-Showing position of ws. (Modified from Hutt, 1960.)

It is suggested that ws is used as the symbol for this gene to distinguish it from the autosomal form (wg) and white skin $(W)$. Three other sex-linked genes involving several matings in each case were used to determine the position of ws.

\section{(i) Barring-winglessness}

The ratio of 94 non-crossovers to 100 crossovers indicated that the genes were too far apart for barring (B) to be of any value in locating ws accurately. (Crossover percentage: $51 \cdot 55 \pm 3 \cdot 59$.)

\section{(ii) Silver-winglessness}

Of the 573 chicks produced only 27 were crossovers. These figures place ws within $4 \cdot 71 \pm 0 \cdot 89$ units of silver $(\mathbf{S})$ but do not indicate which side of silver it lies relative to barring (fig. 1). 
(iii) Slow-feathering-winglessness

As pointed out by Hutt (1960), slow feathering (K) is a very difficult gene for linkage estimation because of its variable expression. Following Hutt's recommendations the birds were only recognised as slow or fast feathering when their day-old classification on wing feathering agreed with the 10-14 days classification on tail feathering.

Unfortunately all the wingless chicks had to be discarded in this study for three reasons:

1. Absence of wing feathers for classification at day old.

2. The survival of only a small proportion to ten days.

3. Abnormal tail feathering in the survivors.

It appeared that in slow-feathered wingless chicks the absence of wings had a compensatory effect on feather growth in the tail so that slow-feathering wingless chicks had more tail development than fast feathering normal ones. Thus only winged female chicks were available for study.

Previous estimates of the distance between $\mathrm{S}$ and $\mathrm{K}$ are extremely variable. Probably the most reliable of these is Hutt's figure of 2.8 units (1960). If $2 \cdot 8$ is accepted for the present tests, then ws must either be 7.5 units from $K$ on the same side as barring or 1.9 units from it on the opposite side. The observed figure of $1 \cdot 27 \pm 0.63$ per cent. would appear to fix it in the latter position (fig. 1).

This tentative fixing of the position of winglessness adds a further gene to Hutt's map of the sex chromosome of the fowl bringing the total to 14 genes of known position.

\section{Summary}

1. A form of winglessness is described in fowls controlled by a sex-linked recessive gene (ws).

2. Its expression varies from almost nil penetrance through various stages of rudimentation to complete absence of legs and wings with a modal type having normal legs but no wings.

3. Linkage tests place the gene $4 \cdot 71 \pm 0 \cdot 89$ units from silver on the opposite side to barring and $1 \cdot 27 \pm 0.63$ units beyond slow feathering.

\section{REFERENGES}

HUTT, в. B. 1949. Genetics of the Fowl. New York, London. McGraw-Hill.

HUTT, F. B. 1960. New Loci in the sex chromosome of the fowl. Heredity, 15, 97-110.

PEASE, M. s. 1962. Wingless poultry. Jour. Hered., 53, 109-110.

WATERS, N. F., AND BYWATERS, J. F. 1943. A lethal embryonic wing mutation in the domestic fowl. Jour. Hered., 34, 213-217. 